\title{
Evidence-based mental health policy
}

Valentina Iemmi, Nicole Votruba, and Graham Thornicroft

\begin{abstract}
This chapter describes evidence-based mental health policy with the help of illustrative examples. After briefly setting the use of research evidence to inform mental health policy within the broader historical context, the second section of the chapter provides a brief description of evidence-based mental health policy and its rationale. The third section illustrates how mental health research may help inform mental health policy, with a description of the research cycle, the policy cycle, their relationship, and the use of epidemiological studies for policymaking. The fourth section provides examples of the use of research evidence in mental health policy at different organizational levels, from the clinical level (micro-level), through the service provision/healthcare facility level (meso-level) and the whole health system level (macro-level), to the global level (mega-level). Finally, the chapter concludes by reflecting on some of the opportunities and challenges that influence evidence-based mental health policy.
\end{abstract}

Key-words: mental health, mental health policy, mental health research, evidence-based policy, implementation science, psychiatric epidemiology

\section{Introduction}

The use of research evidence to inform decisions related to health has been growing since the 1990s. Initially focused on evidence-based medicine, the drive has been expanding to evidence-based health-related policymaking. Since 2004, the World Health Organization 
(WHO) has stressed the importance of putting research into action (WHO, 2004a), supporting evidence-based public health, health services, and health policies (WHO, 2004b). In this view, the WHO has been advocating for the importance of establishing or strengthening knowledge translation of research results to different stakeholders (WHO, 2005a), especially focusing upon the need to pay attention to the diversity of languages and the use of information technologies (WHO, 2009). Evidence-based mental health policy has been fully aligned with this impetus (Cooper, 2003).

This chapter considers evidence-based mental health policymaking with the help of illustrative examples. In the next section of the chapter we shall provide a brief description of evidence-based mental health policy and its rationale. In the third section, we illustrate how mental health research may help to inform mental health policy. In the fourth section we provide examples of the use of research in mental health policy at different organizational levels. Finally, we reflect on the opportunities and challenges of evidence-based mental health policy in the future.

\section{What is evidence-based mental health policy?}

Although mental and substance use disorders account for $7.4 \%$ of the total global burden of disease (Whiteford et al., 2013), only a small proportion of national health budgets is allocated to the treatment and prevention of mental disorders, ranging from $0.5 \%$ in lowincome countries to 5.1\% in high-income countries (WHO, 2013a). This scarcity raises the question of how to best use the available resources not only effectively (what works?), but also efficiently (what is the best use of resources?), and equitably (are all different groups in the population receiving care according to their needs?).

Research evidence may help inform the very difficult choices that policymakers are confronted with, from the design of new mental health policies to their evaluation (Oxman et 
al., 2009), such as identifying effective and efficient mental health interventions and deciding which services to offer, how to better deliver them, how to fund them, and how to evaluate their implementation. Thus, evidence may be crucial to allow policymakers to design mental health services and systems that are more effective, efficient, and equitable (Saxena et al., 2007).

Evidence-based healthcare policymaking, and therefore evidence-based mental health policymaking, is 'an approach to policy decisions that aims to ensure that decision-making is well-informed by the best available research evidence’ (WHO, 2015a). In evidence-based mental health policymaking, recommendations are produced from a combination of research evidence and expert opinions. Once the research evidence is reviewed, expert opinions are crucial in interpreting the evidence and drawing conclusions. Evidence-based recommendations are then provided to policymakers to help inform their final decisions. The process, in theory, is both systematic and transparent (Oxman et al., 2009). The research evidence is reviewed systematically in order to allow a comprehensive coverage of relevant studies and their quality. The process is transparent to permit reproducibility and to ensure that bias and conflict of interests do not affect final decisions. Notwithstanding its transparency, other factors may influence the process, such as population characteristics, needs and preferences, availability of human and financial resources, and environmental and organizational contexts (Brownson et al., 2009a).

\section{From mental health research to mental health policy}

\subsection{What is the research cycle?}

The 'research cycle’ or 'measurement loop’ (Tugwell et al., 1985) was initially designed to illustrate the research process applied to health interventions and health services, but may be 
extended to health policies. The research cycle conceptualizes the research process as an iterative sequence of the following seven stages (Figure 24.1):

1. Identification of the burden of disease, when the burden of disease is quantified (e.g. estimation of the prevalence of depression).

2. Definition of the theories of causation, when possible causes of the burden of disease are identified and assessed (e.g. identification of factors associated with depression).

3. Establishment of the effectiveness, when benefits and harms of potentially feasible interventions are evaluated (e.g. evaluation of the impact of cognitive behavioural therapy for people suffering from depression on clinical outcomes and quality of life).

4. Establishment of the efficiency, when the economic value of potentially feasible (and effective) interventions is evaluated (e.g. evaluation of the cost-effectiveness of cognitive behavioural therapy for people suffering from depression).

5. Implementation, when information from different studies evaluating effectiveness, efficiency, and feasibility are used to draw recommendations to inform decisionmakers' choice, and promising interventions are implemented (e.g. implementation of cognitive behavioural therapy along with drug treatment for people suffering from depression).

6. Evaluation, when interventions that have been implemented are monitored and evaluated to appraise whether they have a positive impact on outcomes and costs, without engendering unintended consequences (e.g. evaluation of the effectiveness and cost-effectiveness of cognitive behavioural therapy along with drug treatment for people suffering from depression as implemented).

7. Reassessment of the burden of disease, when the burden of disease after implementation of the interventions is compared with the initial burden of disease (e.g. estimation of the prevalence of depression after the implementation of the 
intervention). Following this last stage, the cycle will start again with a new sequence of stages.

The seven stages described are a schematic representation of the research process. While they are useful to understand how the research process works, the process is usually more complicated as influenced by many factors such as availability of human and financial resources, and environmental and organizational contexts.

Figure 24.1 The research cycle.

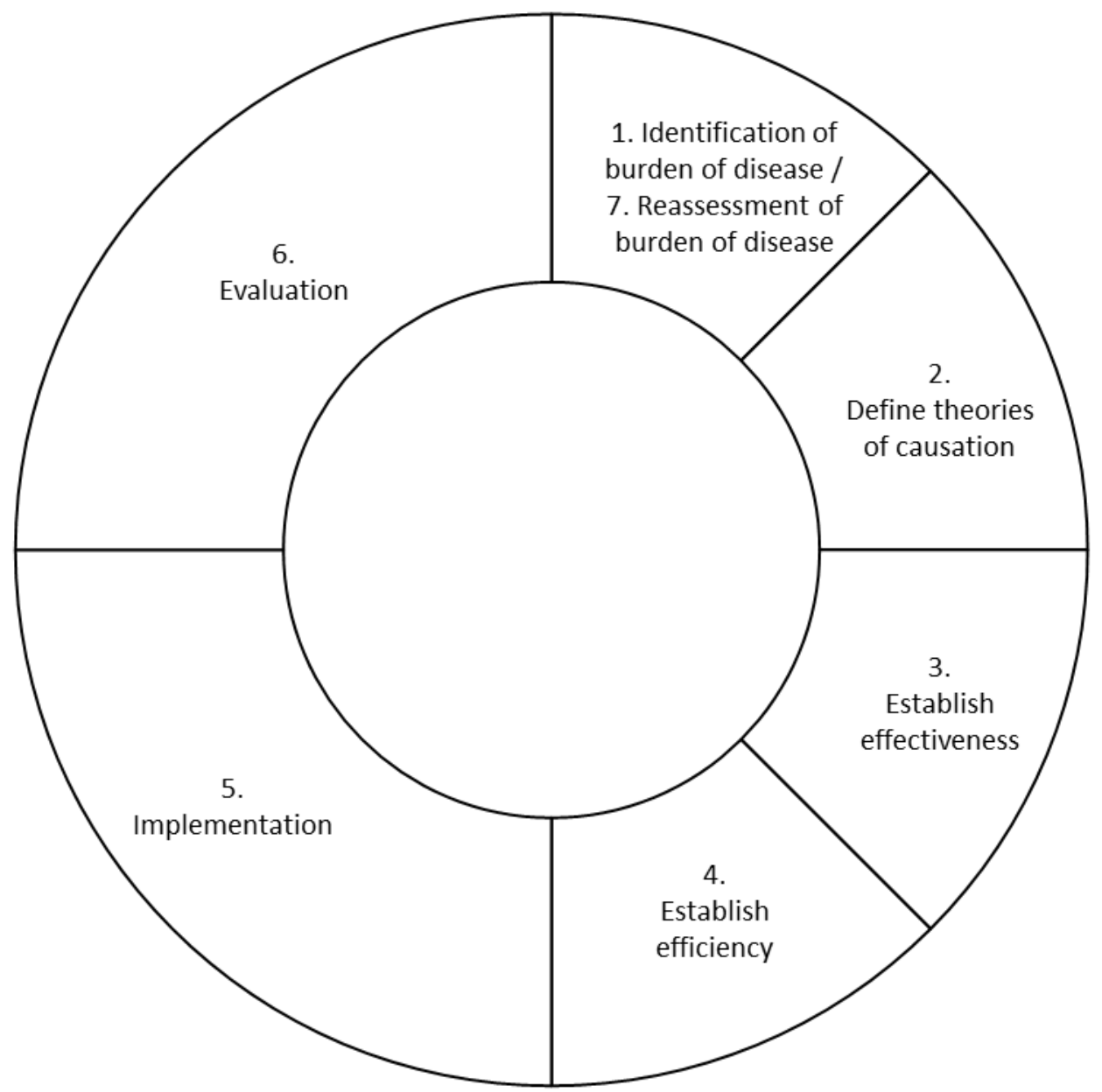

Adapted with permission from Tugwell, P. et al. The measurement iterative loop: a framework for the critical appraisal of need, benefits and costs of health interventions. Journal of Chronic Diseases, 38(4), 339-51.

Copyright @ 1985 Published by Elsevier Inc. DOI: https://doi.org/10.1016/0021-9681(85)90080-3. 


\subsection{What is the policy cycle?}

The most common approach to understand policy process is the 'stages heuristic' model (Sabatier and Jenkins-Smith, 1993), which conceptualizes the policy process as a linear (or cyclical) sequence of four stages (Figure 24.2):

1. Problem identification and issue recognition, when issues to tackle are identified and the agenda set (e.g. recognition of the burden of schizophrenia for individuals and society).

2. Policy formulation, when policies are formulated in order to address the different issues identified during the first stage (e.g. publication of a mental health policy plan including early intervention services for people suffering from schizophrenia).

3. Policy implementation, when policies are implemented (e.g. implementation of early intervention services for people suffering from schizophrenia).

4. Policy evaluation, when policies that have been implemented are evaluated in order to assess whether they attain their objectives without any unintended consequences (e.g. evaluation of the effectiveness and cost-effectiveness of early intervention services for people suffering from schizophrenia). Then, policymakers consider the impact of the policies implemented and decide whether to continue, amend, or abandon them. The end of this last stage leads to the beginning of a new cycle with a new sequence of stages.

As for the research cycle, these four stages are a schematic representation of the policy process which is more complex in reality. While this cycle is useful to understand how the policy process works, we need to recognize that the process is never as linear (or cyclical) and often more similar to 'muddling through' (Lindblom, 1959), as influenced by different factors such as human and financial resources, and environmental and organizational contexts. 
Figure 24.2 The policy cycle.

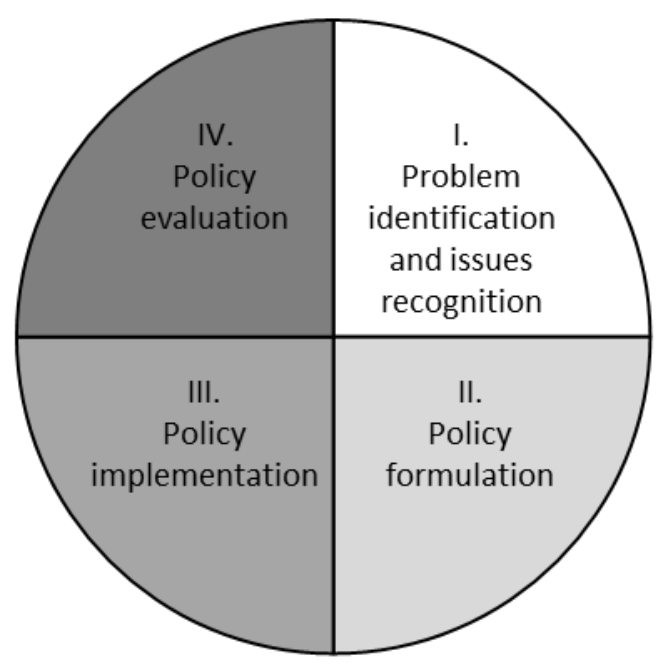

\subsection{How are the research cycle and the policy cycle related?}

In evidence-based mental health policymaking, each of the four stages constituting the policy cycle are informed by different stages of the research cycle (Figure 24.3). The decisions made during the first stage (problem identification and issue recognition) may be informed by studies identifying the burden of disease and defining the theories of causation (research cycle stages 1-2). The decisions made during the second stage (policy formulation) may be informed by studies evaluating the effectiveness and efficiency of interventions, services, or policies (research cycle stages 3-4). The decisions made during the third stage (policy implementation) may be informed by the synthesis of studies on effectiveness, efficiency, and feasibility of interventions, services, or policies (research cycle stage 5). Finally, the decisions made during the fourth and final stage (policy evaluation) may be informed by studies monitoring and evaluating interventions, services, or policies that have been implemented, and by studies quantifying the burden of disease after implementation (research cycle stage 6). While in evidence-based mental health policymaking research evidence 
contributes to each stage of the policy cycle, different types of epidemiological and intervention studies may inform different stages.

Figure 24.3 Relationship between the research cycle and the policy cycle.

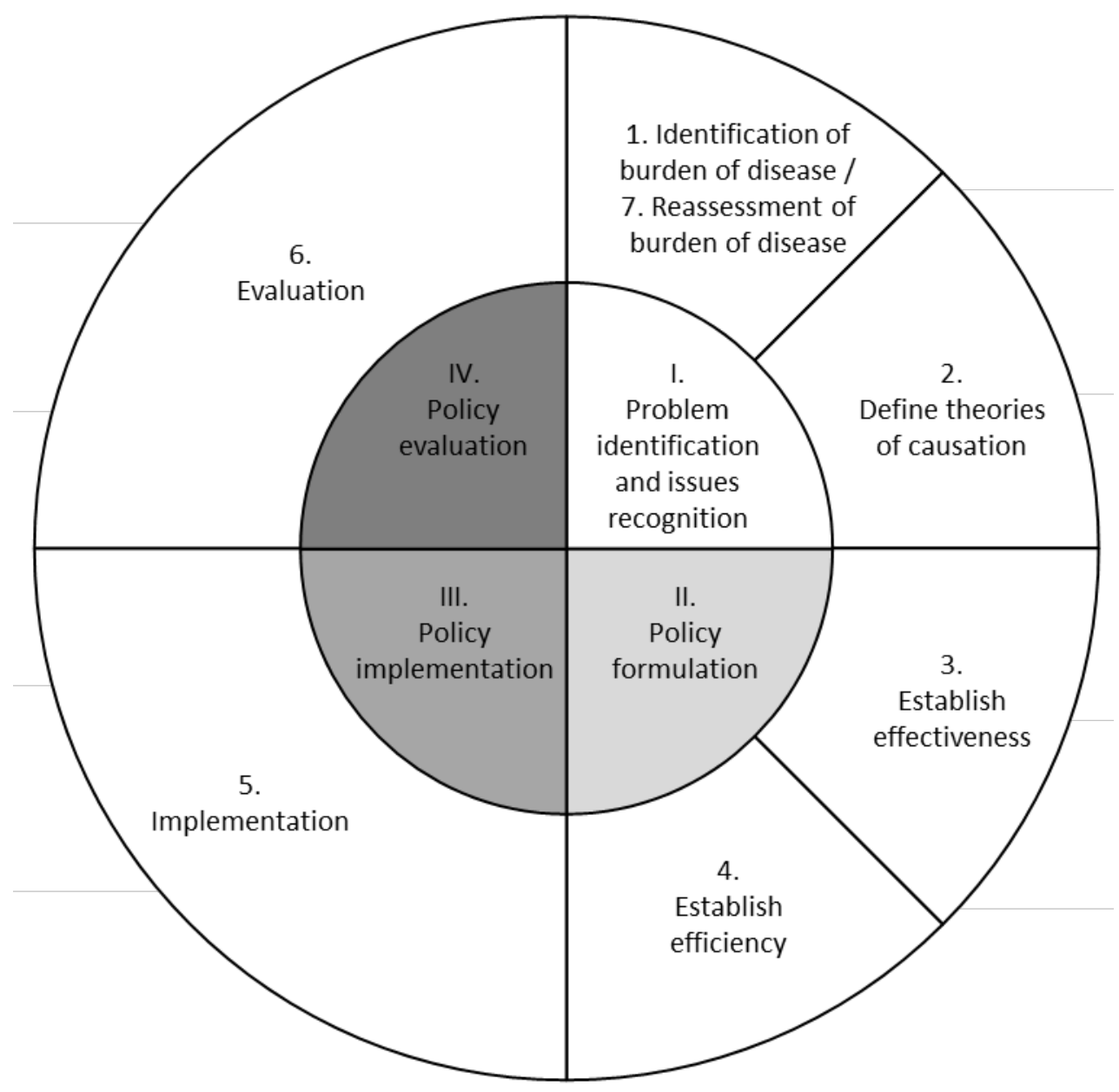

\subsection{What use are epidemiological studies for policy?}

In evidence-based mental health policy, decisions are informed by reviews of the evidence.

Systematic literature review and meta-analysis are considered the gold standard to collect and analyse information from original studies, by using an approach that minimizes bias (see

Chapter 15). However, sometimes non-systematic literature reviews and rapid evidence assessment may be a better choice when human and financial resources are limited, when 
information needs to be produced in a short time frame, or when questions asked are better answered by a non-systematic approach (Government Social Research Unit, 2009).

All types of studies described in the chapters of this book may be used to inform different stages of the policy cycle. However, while different study designs may be included in a literature review, a hierarchy of evidence applies according to the robustness of the study design: systematic reviews and meta-analysis, randomized controlled trials, cohort studies, case-control studies, cross-sectional surveys, ecological and cross-level studies, case series and case reports, and expert opinions. While the inclusion of different study designs in the literature review depends on the stage of the policy cycle, their weight depends on the robustness of their study design (and their quality).

The first stage of the policy cycle (problem identification and issue recognition) may be informed by quantitative studies (e.g. cohort studies, case-control studies, cross-sectional surveys, ecological studies, and cross-level studies) and qualitative studies that may inform decision-makers' choices in the absence of quantitative studies. When more robust evidence is lacking, expert opinions_-including experts from all stakeholders groups (e.g. service users and carers) — may help decision-makers. In addition, this first stage may be informed by costof-illness studies.

The subsequent three stages of the policy cycle (policy formulation, policy implementation, policy evaluation), may be informed preferably by randomized controlled trials, that are considered to be the gold standard for evaluating interventions, services and policies, and by other controlled studies (e.g. non-randomized controlled trials, controlled before-after studies, and controlled interrupted time series studies with multiple points of evaluation after the intervention). In the absence of controlled studies, non-controlled studies (e.g. cross-sectional surveys, ecological studies, and cross-level studies) and qualitative studies may inform decision-makers' choices. When more robust evidence is missing, expert 
opinions may inform decision-makers’ choices. Moreover, those three stages may be

informed by economic evaluations, conducted along each of the previous study designs, or

economic modelling.

More recently, the increasing number of systematic reviews and meta-analysis of

reviews has gained the interest of policymakers. In particular, open-access databases of

systematic reviews of interventions have been created (e.g. the Cochrane Library and the

Campbell Collaboration Library). Table 24.1 provides examples of different types of studies

that may be used to inform the four stages of the policy cycle.

Table 24.1 Example of study types used to inform the policy cycle

\begin{tabular}{|c|c|c|}
\hline Policy cycle & Research cycle & Example of relevant epidemiological studies \\
\hline $\begin{array}{l}\text { I. Problem } \\
\text { identification and } \\
\text { issue recognition }\end{array}$ & $\begin{array}{l}\text { 1. Identification of the } \\
\text { burden of disease (and } \\
\text { 7. Reassessment of the } \\
\text { burden of disease) }\end{array}$ & $\begin{array}{l}\text { - Systematic review and meta-analysis of cohort studies to estimate mortality among people with mental } \\
\text { disorders, and their differences by type of death and diagnosis (Walker et al., 2015) } \\
\text { Global Burden of Diseases, Injuries, and Risk Factors Study 2010, to estimate the burden of disease } \\
\text { attributable to mental and substance use disorders (Whiteford et al., 2013) } \\
\text { - } \quad \text { National survey to estimate the prevalence of schizophrenia-related disability in the Chinese population, } \\
\text { factors associated with differences in prevalence rates between women and men and across geographic } \\
\text { regions (Liu et al., 2015) } \\
\text { - Cross-sectional surveys to estimate the prevalence of perinatal mental disorders, their determinants, and } \\
\text { - } \quad \text { Coir association with preventive healthcare use in northern Viet Nam (Fisher et al., 2010) } \\
\text { - Cost of illness of schizophrenia in Japan, including direct and indirect economic costs (Sado et al., 2013) } \\
\text { Cost of illness of autism in the UK and US, including direct, indirect, and lifetime societal economic costs } \\
\text { (Buescher et al., 2014) }\end{array}$ \\
\hline & $\begin{array}{l}\text { 2. Define theories of } \\
\text { causation }\end{array}$ & $\begin{array}{l}\text { - Systematic review of epidemiological studies to exam the relationship between poverty and common mental } \\
\text { disorders in developing countries (Lund et al., 2010) } \\
\text { - } \quad \text { Prospective study with 2-year follow-up evaluating the influence of presenteeism on depression and } \\
\text { sickness absences due to mental disease in a cohort of Japanese workers (Suzuki et al., 2015) } \\
\text { - } \quad \text { Longitudinal national survey to study risk factors for poor longitudinal outcomes in individuals with } \\
\text { untreated common mental disorders in the US (Henriksen et al., 2015) } \\
\text { - Longitudinal surveys to assess unemployment rates among individuals with mental health problems before } \\
\text { and during the current economic recession in Europe (Evans-Lacko et al., 2013a) } \\
\text { Longitudinal surveys to study the association between public knowledge, attitudes, and behaviours and the } \\
\text { internalization of stigma among people with mental health problems in Europe (Evans-Lacko et al., 2012) }\end{array}$ \\
\hline $\begin{array}{l}\text { II. Policy } \\
\text { formulation }\end{array}$ & $\begin{array}{l}\text { 3. Establish } \\
\text { effectiveness }\end{array}$ & $\begin{array}{l}\text { - Systematic review and meta-analysis of randomized and non-randomized controlled trials to evaluate the } \\
\text { effectiveness of psychosocial interventions for perinatal common mental disorders delivered by providers } \\
\text { who are not mental health specialists in developing countries (Clarke et al., 2013) } \\
\text { - } \quad \text { Randomized controlled trial to evaluate the effectiveness of a community-based care intervention for people } \\
\text { with schizophrenia and their caregivers in India (Chatterjee et al., 2014) } \\
\text { Before-after study to evaluate the impact of Time to Change's social marketing interventions on stigma in } \\
\text { England (Evans-Lacko et al., 2013b) }\end{array}$ \\
\hline & 4. Establish efficiency & $\begin{array}{l}\text { Economic evaluation alongside a randomized controlled trial to evaluate the effectiveness and cost- } \\
\text { effectiveness of cognitive behavioural therapy in adolescents suffering with depression in the Netherlands } \\
\text { (Stikkelbroek et al., 2013) }\end{array}$ \\
\hline
\end{tabular}




\begin{tabular}{|c|c|c|}
\hline & & 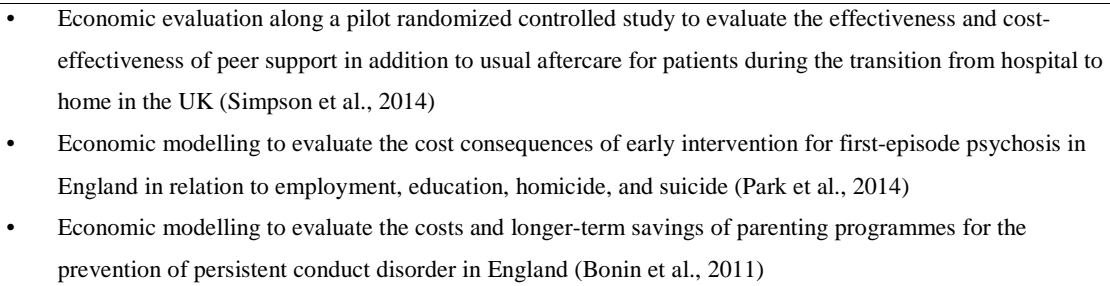 \\
\hline $\begin{array}{l}\text { III. Policy } \\
\text { implementation }\end{array}$ & 5. Implementation & $\begin{array}{ll}\text { - } & \text { See 'Policy formulation (establish effectiveness)' } \\
\text { - } & \text { See 'Policy formulation (establish efficiency)' } \\
\text { - } & \text { Qualitative study exploring reasons for non-adherence to medication in people with schizophrenia in } \\
\text { - } & \text { Ethiopia (Teferra et al., 2013) } \\
& \text { postnatitative study exploring the health visitors' perceptions on cognitive behavioural therapy to treat }\end{array}$ \\
\hline $\begin{array}{l}\text { IV. Policy } \\
\text { evaluation }\end{array}$ & 6. Evaluation & 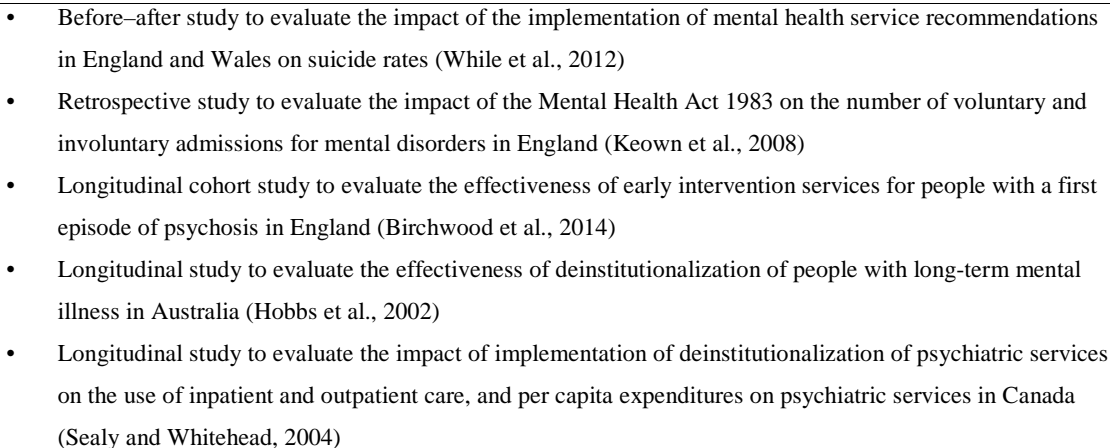 \\
\hline
\end{tabular}

\section{Evidence-based mental health policy in context}

Evidence-based mental health policy can inform decision-makers at any level, from the clinical level (micro-level), through service provision/healthcare facility level (meso-level) and the whole health system level (macro-level), to the global level (mega-level). While the following sections will provide examples of evidence-based mental health policy at these four levels, we would like to emphasize that all levels are closely interrelated and they help inform each other.

\subsection{Micro-level}

Evidence may help inform decision-makers at the clinical level on the best available mental healthcare. An outstanding example is provided by the National Institute for Health and Care Excellence (NICE) in England. NICE, established in 1999, is an independent agency responsible for developing national guidelines to help health and social care professionals ‘deliver the best possible care based on the best available evidence’ (NICE, 2013a). Clinical 
guidelines are produced through an iterative process including systematic reviews and metaanalysis of epidemiological and intervention studies, and experts' opinion (NICE, 2014). For example, the NICE guideline on management and support of children and young people on the autism spectrum, developed by a Guideline Development Group of experts on autism using a series of systematic review of the evidence and economic models, summarizes recommendations on the best available psychological, pharmacological, and biomedical interventions aimed to support children and young people on the autism spectrum and their carers (NICE, 2013b).

Similar agencies are developing around the world, such as the National Center for Health Technology Excellence (CENETEC-Salud) in Mexico. The CENETEC-Salud, established in 2004, is an independent agency aiming to produce recommendations on the best care based on the best available evidence to help in informing clinical decisions and guaranteeing the best use of resources. The guidelines are produced with a process similar to the iterative process used by NICE, including review of the evidence and expert opinion. For example, the CENETEC-Salud guideline on diagnosis and treatment of depression in adults provides recommendations on the best diagnostic practices and the best available pharmacological and non-pharmacological interventions for the treatment of depression in adults (Secretaría de Salud, 2009).

\subsection{Meso-level}

Evidence may help inform decision-makers at the service provision/healthcare facility level, from commissioners to providers, on the best available mental health services. An ambitious example is the National Service Framework for Mental Health (NSF-MH) in England (Department of Health, 1999). The NSF-MH, published by the Department of Health in 1999, set a 10-year agenda for improving adults’ mental healthcare through the description of 'national standards for mental health, what they aim to achieve, how they should be 
developed and delivered and how to measure performance in every part of the country' (Department of Health, 1999, p. 1). The NSF-MH was based on review of evidence and experts’ opinion of an External Reference Group (Thornicroft, 2000). The process helped identify seven standards for mental health (mental health promotion, primary care and access to services (comprising two standards), effective services for people with severe mental illness (comprising two standards), caring about carers, and preventing suicide) that were subsequently implemented across England.

The implementation of the NSF-MH was evaluated through the years using different study designs. For example, a before-after study found a decrease in suicide rates in areas having implemented NSF-MH recommendations (While et al., 2012). Following recommendations of the NSF-MH, crisis resolution and home treatment teams were introduced in England to reduce inpatient admissions and readmissions of people undergoing a severe mental health crisis. An observational study evaluating their implementation found a reduction in hospital admissions across England (Glover et al., 2006). Similarly, following recommendations of the NSF-MH, assertive community treatment (ACT) teams were introduced in England to reduce inpatient admissions of people suffering with severe mental disorders, a high use of inpatient care but difficult engagement with standard mental health services. A randomized controlled trial evaluating the implementation of ACT found no decrease in use of inpatient care 3 years after implementation of ACT, but better engagement with the service (Killapsy et al., 2009).

\subsection{Macro-level}

Evidence may help inform decision-makers at the whole health system level, on broader issues from best available models of organization of services and coordination, through workforce organization and training, to funding, quality measurement, and governance. Globally, health systems have overlooked mental disorders for too long. This is reflected in 
the limited, yet in the last decade, steadily growing number of countries with specific mental health policies. The WHO Mental Health Atlas reports in 2011 that only $60 \%$ of nations worldwide have a mental health policy, with a large majority of those countries being in highincome settings (WHO, 2011). Mental health policies are specific to each country, and influenced by the specific political, economic, social, and cultural context. For example, in low- and middle-income countries frequently critical factors such as poverty, conflict, or political instability add to the complexity of the process (Sutcliffe and Court, 2005).

An outstanding example of an evidence-based mental health policy at the health system level is presented by Ethiopia. Notwithstanding ranking among the poorest countries in the world (World Bank, 2015) and being so restrained in economic and natural resources, in the last decades Ethiopia has made great efforts and improvements in scaling up the overall health system, as well as mental health system, by leading a challenging evidence-based policy (Wamai, 2009). A first-ever national health policy, and consecutive health sector development plans, were developed from the early 1990s. As part of a mental health policy, in 2012 the Ministry of Health recognized mental health as a major health priority and adopted an ambitious mental health strategy (Federal Democratic Republic of Ethiopia Ministry of Health, 2012). Integrated in the national health policy, the strategy focuses on primary healthcare services and decentralization, in line with global evidence-based mental health recommendations (WHO, 2008, 2013b). The Ethiopian government acknowledges an expected rise in mental illness in the next years, and has defined mental health as a major health priority (Federal Democratic Republic of Ethiopia Ministry of Health, 2012). The gradual implementation of the new evidence-based mental health policy is an important achievement (Fekadu and Thornicroft, 2014). However, the change from a poorly developed mental health system to scaling up mental health services is a large undertaking, particularly considering other competing health system challenges. For Ethiopia to continue following its 
ambitious goals, research capacity would need to continue to increase and thus the evidence produced by local and regional researchers.

\subsection{Mega-level}

Evidence may help inform decision-makers at the global level, on overarching recommendations from the best available care, through models of service provision/healthcare facility, to mental health systems. International organizations as the WHO and the Organization for Economic Cooperation and Development (OECD) have taken a leading role in the field of health and mental health, by providing evidence-based guidelines and policies (Dua et al., 2011; OECD, 2014). While global guidelines and policies can be ground-breaking landmarks, their legislative power depends on the political commitment of each state, as well as the implementability of policies in different political, economic, social, and cultural settings. So far, the majority of the evidence generated and contributing to mental health research and policies came from developed countries, and greatly neglected the evidence on needs and specific conditions in developing countries. While $85 \%$ of all people with mental health problems live in low- and middle-income countries, only $10 \%$ of the world’s medical research addresses these (Lancet Global Mental Health Group, 2007). Thus, evidence-based global mental health policies demand focusing on these neglected parts of the world.

In 2000, the WHO launched the Project Atlas in order to gain and disseminate global evidence on mental health resources (Saraceno and Saxena, 2002). The following year, the WHO World Health Report 2001 provided a first comprehensive review of the existing evidence on the global burden of mental and substance use disorders, mental health policies, and mental health service provision (WHO 2001a). In the same year, the first global Mental Health Atlas was published with information on mental health resources as individual country profiles (WHO, 2001b), and sequentially updated (WHO, 2005b, 2011). In 2005, the WHO 
Assessment Instrument for Mental Health System (WHO-AIMS) was designed to gather comprehensive information on mental health systems in order to establish mental health country profiles in low- and middle-income countries (WHO 2015b). Similarly, the OECD (2015) produced mental health country profiles for some OECD countries.

With the aim to scale up mental health services especially in low- and middle-income countries, the WHO launched in 2008 the Mental Health Gap Action Programme (mhGAP), designed as a framework for country action, including an integrated package of key interventions for mental, neurological, and substance use disorders to scale up coverage especially in resource-limited settings (WHO 2008, 2010). At present, ‘coverage’ is conceptualized as simply the proportion of people with mental disorders who receive treatment, and we expect that in the future a more detailed understanding of the levels of coverage will be developed as shown in Figure 24.4 (De Silva et al., 2014).

Figure 24.4 Levels of service coverage.

De Silva, M., Cohen, A., and Patel, V. (2014). Evaluation of interventions in the real world. In: Thornicroft, G. and Patel, V. (eds.). Global mental health trials, pp. 282-302. Oxford: Oxford University Press. Adapted from Tanahashi T (1978) Health service coverage and its evaluation. Bull World Health Organ, 56(2):295-303. Published by Oxford University Press on behalf of the International Epidemiological Association (C) The Author 2014. This is an Open Access article distributed under the terms of the Creative Commons Attribution License (http://creativecommons.org/licenses/by/3.0/), which permits unrestricted reuse, distribution, and reproduction in any medium, provided the original work is properly cited. DOI: https://academic.oup.com/ije/articlelookup/doi/10.1093/ije/dyt191.

The mhGAP package provides evidence-based technical guidance, interventions, tools, and training, which must be adapted to national, regional, and local contexts. Priorities in mental, neurological, and substance use disorders have been identified based on the best available scientific and epidemiological evidence, and barriers for scaling up mental 
healthcare have been considered. A further milestone in evidence-based mental health policymaking is the WHO Mental Health Action Plan 2013-2020, a global strategy setting objectives, targets, and proposed actions for member states and international partners (WHO, 2013b). While the number and extent of evidence-based global mental health policies is growing, epidemiological research needs to continue contributing by keeping both the local and global focus on research.

\section{Opportunities and challenges}

Policymaking is a complex, non-linear, and erratic process. Policy decisions are difficult to predict, as details are influenced by a range of stakeholders and circumstances. Evidencebased policymaking attempts and contributes to making the policy process more transparent. Researchers can actively influence evidence-based policymaking, but they need to consider various opportunities and challenges that may favour or hinder the process, such as the quality of the research evidence, the knowledge exchange process, timing and accessibility, stigma, and the heterogeneity of mental health as a policy issue.

The premise for evidence-based policymaking is comprehensive, robust evidence, which is mainly provided by systematic reviews, randomized controlled trials, and intervention studies. However, there is still a research gap for some diseases in specific contexts and regions (e.g. suicide (WHO Regional Office for Europe, 2012)) or effectiveness and efficiency, particularly in low- and middle-income settings (Knapp et al., 2006). As the evidence necessarily stems from context-specific observations, it must vice versa be used in a very context-specific way by policymakers (Sutcliffe and Court, 2005). However, underfinancing of the academic and mental health sector in low- and middle-income settings contributes to the lack of context-related evidence from local researchers (Razzouk et al., 2009). More research is needed, providing 'hard' evidence, based on statistical data, as well 
as 'soft' evidence (Brownson et al., 2009b), such as stakeholder reports or patient monitoring (Mackenzie, 2014). In addition, more public engagement is needed from all stakeholders including service users and carers, as only then can evidence-based mental health policy claim full credibility and authenticity (Collins et al., 2011).

Another challenge lies in the process of knowledge exchange from researchers to policymakers. Comprehensive research findings need to be communicated to policymakers in a compact, clear way, understandable for lay audience, for example, in policy papers or policy briefings (Young and Quinn, 2002). Remarkable tools for knowledge exchange in the evidence-based policymaking process are online resources. Social media such as Twitter, Facebook, YouTube, and other social platforms are crucial for research communication, public information campaigns, and targeted dissemination (Stone et al., 2001). Yet, access to the Internet and online tools may constitute an additional technical challenge, particularly for researchers in low- and middle-income countries (Razzouk et al., 2009). In non-democratic political systems, additional challenges can arise through restricted academic freedom and limited freedom of the press. For policymakers to be able to take advantage from the evidence, political continuity and stability of the political system need to be assured, while conflict and volatility have proven to be an obstacle (Sutcliffe and Court, 2005). In addition, over the last decade, multiple evidence-based online tools have been developed to inform the policy process, illustrating how information technology is supporting the drive. Among them, at the micro-level, NICE Pathways (NICE, 2015) is an online tool providing access to NICE clinical guidelines and other NICE tools in England. At the meso-level, PsyMaptic (University of Cambridge, 2015) is an epidemiological prediction tool for first-episode psychosis in England and Wales. At the macro- and mega-levels, GBD Compare (Institute for Health Metrics and Evaluation, 2015) is an online tool for estimating the burden of disease of multiple mental and physical conditions and OneHealth (IHP+, 2015) is an online tool for 
developing financing scenarios at country level. However, as previously mentioned, access to the Internet may represent a challenge, particularly in low- and middle-income countries (Razzouk et al., 2009).

An important facilitator to the evidence-based policymaking process is timing and accessibility of the evidence (Oliver et al., 2014). Policymakers often need to decide rapidly on policies they are not experts on, so they need to have access to the specifically required, distinct information quickly and easily (Cable, 2004). Researchers need to use this time window and can facilitate the process by continuous networking and interaction with policymakers (Innvaer et al., 2002). Collaboration with, and continuous involvement of, policymakers during all stages of the research process builds up well-established links and trust, and can facilitate communication (Jenkins et al., 2007).

Networking, together with knowledge sharing and public campaigns, can also facilitate overcoming the additional challenge of stigma associated to mental illness which is peculiar to mental health policymaking (Evans-Lacko et al., 2012). An additional global challenge for evidence-based mental health policymaking stands in the complexity and heterogeneity of mental health as a policy issue. To date, mental health research has been unable to build a unified voice and framework for public actions, which acts as a major challenge for translating research into policy (WHO, 2013a). The use of a unified voice will facilitate communication.

For more efficient and effective evidence-based policymaking, additional research is needed in mental health policy analysis, particularly on the policy process, and the impact and effectiveness of the use of research to inform the policy process (Oliver et al., 2014). A research gap has also been identified in how to change public and policymakers' attitudes with regard to mental health stigma (Mackenzie, 2014), and more 'action-oriented research' 
is needed, emanating from mental health workers' priorities, in order to contribute and advise regional health policy and practice (see Chapter 3).

\section{Conclusion}

Mental health policy is increasingly supported by research evidence, through a process both systematic and transparent. Research evidence is used to inform decision-makers throughout all stages of the policy process, from problem identification and issue recognition, through policy formulation, to policy implementation, and evaluation. Different types of studies can inform each stage, feeding the multiple aspects of the policy process, including both quantitative and qualitative studies. Evidence can inform decision-makers at every level, from clinical care through service provision/healthcare facility level, to national and global health systems. However, opportunities and challenges need to be considered during the process, such as quality of research evidence, knowledge exchange process, timing and accessibility, stigma, and heterogeneity of mental health as a policy issue. In particular, the use of information technologies is promising in creating a platform for timey and accessible knowledge exchange between researcher and policymakers.

Evidence-based mental health policymaking is crucial to scale up acceptable, effective, efficient, and equitable mental healthcare, services, and systems. However, further evidence to support this process is required not only on mental disorders, mental health interventions, and mental health services, but also on mental health policies and mental health policy process. The call for evidence is paramount in low- and middle-income countries where evidence is particularly scarce. The impact of research on policy has never before been so direct, and the role of researchers in designing and disseminating sound results so crucial.

\section{Practical exercises}


1. Policymakers in your country are working on a national plan to improve perinatal maternal mental healthcare. You wish to provide them with the best available evidence in order to facilitate their choices.

a. Which types of studies would you review to inform them about the problem, in terms of burden of perinatal maternal mental health in your country, and in terms of causes of perinatal maternal mental health?

b. Which types of studies would you review to inform them about the effectiveness of interventions for perinatal maternal mental health?

c. Which types of studies would you review to inform them about the efficiency of interventions for perinatal maternal mental health?

d. Which types of studies would you review to inform them about issues related with the implementation of interventions for perinatal maternal mental health?

e. $\quad$ Once the national plan has been published, and recommended services implemented across your country, policymakers are interested in knowing whether the national plan has a positive impact. Which types of studies would you use to inform them about the effectiveness and efficiency of services for perinatal maternal mental health that have been implemented across the country?

2. Imagine that you have received a grant for a project aiming to increase the influence of evidence-based mental health policies in a low-income setting. You need to set up a multidisciplinary team that represents all relevant stakeholders, who would help you in planning and implementing a mental health strategy to scale up mental health services in that country.

a. Who are your relevant stakeholders? How will you involve them? 
b. What are the levels of mental health policymaking that you need to consider for your strategy? How will you consider each of the levels in your strategy?

c. What are the essential factors to increase the influence of evidence-based mental health policies? What challenges will you need to consider? Which facilitators can help your work?

\section{References}

Birchwood, M., Lester, H., McCarthy, L., Jones, P., Fowler, D., Amos, T., et al. (2014). The UK national evaluation of the development and impact of Early Intervention Services (the National EDEN studies): study rationale, design and baseline characteristics. Early Intervention in Psychiatry, 8, 59-67.

Bonin, E.M., Stevens, M., Beecham, J., Byford, S., and Parsonage, M. (2011). Costs and longer-term savings of parenting programmes for the prevention of persistent conduct disorder: a modelling study. BMC Public Health, 11, 803.

Brown, M. and Reynolds, P. (2014). Delivery of CBT to treat postnatal depression: health visitors’ perceptions. Community Practitioner, 87, 26-29.

Brownson, R.C., Fielding, J.E., Maylahn, C.M. (2009a). Evidence-based public health: a fundamental concept for public health practice. Annual Review of Public Health, 30, 175-201.

Brownson, R.C., Chriqui, J.F., and Stamatakis, K.A. (2009b). Understanding evidence-based public health policy. American Journal of Public Health, 99, 1576-1583.

Buescher, A.V., Cidav, Z., Knapp, M., and Mandell, D.S. (2014). Costs of autism spectrum disorders in the United Kingdom and the United States. JAMA Pediatrics, 168, 721728. 
Cable, J. (2004). Evidence and UK politics. In: Young, J. and Court, J. (eds.). Research and policy in development: does evidence matter? An ODI Meeting Series, pp. 11-13. London: Overseas Development Institute.

Chatterjee, S., Naik, S., John, S., Dabholkar, H., Balaji, M., Koschorke, M., et al. (2014). Effectiveness of a community-based intervention for people with schizophrenia and their caregivers in India (COPSI): a randomised controlled trial. Lancet, 383, 13851394.

Clarke, K., King, M., and Prost, A. (2013). Psychosocial interventions for perinatal common mental disorders delivered by providers who are not mental health specialists in lowand middle-income countries: a systematic review and meta-analysis. PLoS Medicine, 10, e1001541.

Collins, P.Y., Patel, V., Joestl, S.S., March, D., Insel, T.R., and Daar, A.S. (2011). Grand challenges in global mental health: A consortium of researchers, advocates and clinicians announces here research priorities for improving the lives of people with mental illness around the world, and calls for urgent action and investment. Nature, 475, 27-30.

Cooper, B. (2003). Evidence-based mental health policy: a critical appraisal. British Journal of Psychiatry, 183, 105-113.

Department of Health (2009). The national service framework for mental health: modern standards and service models. London: Department of Health.

De Silva, M., Cohen, A., and Patel, V. (2014). Evaluation of interventions in the real world. In: Thornicroft, G. and Patel, V. (eds.). Global mental health trials, pp. 282-302. Oxford: Oxford University Press.

Dua, T., Barbui, C., Clark, N., Fleischmann, A., Poznyak, V., van Ommeren, M., et al. (2011). Evidence-based guidelines for mental, neurological, and substance use 
disorders in low- and middle-income countries: summary of WHO recommendations. PLoS Medicine, 8, e1001122.

Evans-Lacko, S., Brohan, E., Mojtabai, R., and Thornicroft, G. (2012). Association between public views of mental illness and self-stigma among individuals with mental illness in 14 European countries. Psychological Medicine, 42, 1741-1752.

Evans-Lacko, S., Knapp, M., McCrone, P., Thornicroft, G., and Mojtabai, R. (2013a). The mental health consequences of the recession: economic hardship and employment of people with mental health problems in 27 European countries. PLoS One, 8, e69792.

Evans-Lacko, S., Malcolm, E., West, K., Rose, D., London, J., Rüsch, N., et al. (2013b). Influence of Time to Change’s social marketing interventions on stigma in England 2009-2011. British Journal of Psychiatry, Supplement, 55, s77-s88.

Federal Democratic Republic of Ethiopia Ministry of Health (2012). National mental health strategy 2012/13-2015/16. Addis Ababa, Ethiopia: Federal Democratic Republic of Ethiopia Ministry of Health.

Fekadu, A. and Thornicroft, G. (2014). Global mental health: perspectives from Ethiopia. Global Health Action, 7, 25447.

Fisher, J., Tran, T., La, B.T., Kriitmaa, K., Rosenthal, D., and Tran, T. (2010). Common perinatal mental disorders in northern Viet Nam: community prevalence and health care use. Bulletin of the World Health Organization, 88, 737-745.

Glover, G., Arts, G., Babu, K.S. (2006). Crisis resolution/home treatment teams and psychiatric admission rates in England. British Journal of Psychiatry, 189, 441-445. Government Social Research Unit (2009). Rapid evidence assessment toolkit. London: Government Social Research Service. 
Henriksen, C.A., Stein, M.B., Afifi, T.O., Enns, M.W., Lix, L.M., and Sareen, J. (2015). Identifying factors that predict longitudinal outcomes of untreated common mental disorders. Psychiatric Services, 66, 163-170.

Hobbs, C., Newton, L., Tennant, C., Rosen, A., and Tribe, K. (2002). Deinstitutionalization for long-term mental illness: a 6-year evaluation. Australian and New Zealand Journal of Psychiatry, 36, 60-66.

Innvaer, S., Vist, G., Trommald, M., and Oxman, A. (2002). Health policy-makers’ perceptions of their use of evidence: a systematic review. Journal of Health Services Research \& Policy, 7, 239-244.

Jenkins, R., McDaid, D., Brugha, T., Cutler, P., and Hayward, R. (2007). The evidence base in mental health policy and practice. In: Knapp, M., McDaid, D., Mossialos, E., and Thornicroft, G. (eds.). Mental health policy and practice across Europe: the future direction of mental health care, pp. 100-125. Maidenhead: McGraw Hill Open University Press.

Keown, P., Mercer, G., and Scott, J. (2008). Retrospective analysis of hospital episode statistics, involuntary admissions under the Mental Health Act 1983, and number of psychiatric beds in England 1996-2006. British Medical Journal, 337, a1837.

Killaspy, H., Kingett, S., Bebbington, P., Blizard, R., Johnson, S., Nolan, F., et al. (2009). Randomised evaluation of assertive community treatment: 3-year outcomes. British Journal of Psychiatry, 195, 81-82.

Knapp, M., Funk, M., Curran, C., Prince, M., Grigg, M., and McDaid, D. (2006). Economic barriers to better mental health practice and policy. Health Policy and Planning, 2, $157-170$.

IHP+ (2015). OneHealth. International Health Partnership. http://www.internationalhealthpartnership.net/en/tools/one-health-tool 
Institute for Health Metrics and Evaluation (2015). GBD Compare. Institute for Health Metrics and Evaluation. http://vizhub.healthdata.org/gbd-compare

Lancet Global Mental Health Group (2007). Scale up services for mental disorders: a call for action. Lancet, 370, 1241-1252.

Lindblom, C.E. (1959). The science of “muddling through”. Public Administration Review, 19, 79-88.

Liu, T., Zhang, L., Pang, L., Li, N., Chen, G., and Zheng, X. (2015). Schizophrenia-related disability in China: prevalence, gender, and geographic location. Psychiatric Services, 66, 249-257.

Lund, C., Breen, A., Flisher, A.J., Kakuma, R., Corrigall, J., Joska, J.A., et al. (2010). Poverty and common mental disorders in low and middle income countries: a systematic review. Social Science \& Medicine, 71, 517-528.

Mackenzie, J. (2014). Global mental health from a policy perspective: a context analysis characterising mental health and recommending engagement strategies for the Mental Health Innovation Network. London: Overseas Development Institute.

National Institute for Health and Care Excellence (2013a). NICE charter. NICE. https://www.nice.org.uk/Media/Default/About/Who-we-are/NICE_Charter.pdf

National Institute for Health and Care Excellence (2013b). Autism: the management and support of children and young people on the autism spectrum (CG 170). London: NICE.

National Institute for Health and Care Excellence (2014). Developing NICE guidelines: the manual. London: NICE.

National Institute for Health and Care Excellence (2015). NICE pathways. NICE. http://pathways.nice.org.uk 
Organisation for Economic Cooperation and Development (2014). Making mental health count: the social and economic costs of neglecting mental health care. Paris: OECD.

Organisation for Economic Cooperation and Development (2015). Mental health systems in OECD countries. OECD. http://www.oecd.org/els/health-systems/mental-healthsystems.htm

Oliver, K., Innvar, S., Lorenc, T., Woodman, J., and Thomas, J. (2014). A systematic review of barriers to and facilitators of the use of evidence by policymakers. BMC Health Services Research, 14, 2.

Oxman, A.D., Lavis, J.N., Lewin, S., and Fretheim, A. (2009). SUPPORT tools for evidenceinformed health Policymaking (STP). 1: What is evidence-informed policymaking? Health Research Policy and Systems, 7(Suppl 1), S1.

Park, A.L., McCrone, P., and Knapp, M. (2014). Early intervention for first-episode psychosis: broadening the scope of economic estimates. Early Intervention in Psychiatry, 10, 144-151.

Razzouk, D., Sharan, P., Gallo, C., Gureje, O., Lamberte, E.E., de Jesus Mari, J., et al. (2009). Scarcity and inequity of mental health research resources in low- and middleincome countries: a global survey. Health Policy, 94, 211-20.

Sabatier, P. and Jenkins-Smith, H.C. (eds.) (1993). Policy change and learning: an advocacy coalition approach. Boulder, CO: Westview Press.

Sado, M., Inagaki, A., Koreki, A., Knapp, M., Kissane, L.A., Mimura, M., and Yoshimura, K. (2013). The cost of schizophrenia in Japan. Neuropsychiatric Disease and Treatment, 9, 787-798.

Saraceno, B. and Saxena, S. (2002). Mental health resources in the world: results from Project Atlas of the WHO. World Psychiatry, 1, 40-44. 
Saxena, S., Thornicroft, G., Knapp, M., and Whiteford, H. (2007). Resources for mental health: scarcity, inequity, and inefficiency. Lancet, 370, 878-89.

Sealy, P. and Whitehead, P.C. (2004). Forty years of deinstitutionalization of psychiatric services in Canada: an empirical assessment. Canadian Journal of Psychiatry, 49, 249-257.

Secretaría de Salud (2009). Diagnóstico y tratamiento del trastorno depresivo de 18 a 59 años de edad. Mexico: Secretaría de Salud, Mexico City.

http://www.cenetec.salud.gob.mx/descargas/gpc/CatalogoMaestro/161_GPC_TRASTORNO _DEPRESIVO/Imss_161ER.pdf

Simpson, A., Flood, C., Rowe, J., Quigley, J., Henry, S., Hall, C., et al. (2014). Results of a pilot randomised controlled trial to measure the clinical and cost effectiveness of peer support in increasing hope and quality of life in mental health patients discharged from hospital in the UK. BMC Psychiatry, 14, 30.

Stikkelbroek, Y., Bodden, D.H., Deković, M., and van Baar, A.L. (2013). Effectiveness and cost effectiveness of cognitive behavioral therapy (CBT) in clinically depressed adolescents: individual CBT versus treatment as usual (TAU). BMC Psychiatry, 13, 314.

Stone, D., Maxwell, S., and Keating, M. (2001). Bridging research and policy: an international workshop. Warwick: Warwick University.

Sutcliffe, S. and Court, J. (2005). Evidence-based policymaking: What is it? How does it work? What relevance for developing countries? London: Overseas Development Institute.

Suzuki, T., Miyaki, K., Song, Y., Tsutsumi, A., Kawakami, N., Shimazu, A., et al. (2015). Relationship between sickness presenteeism (WHO-HPQ) with depression and 
sickness absence due to mental disease in a cohort of Japanese workers. Journal of Affective Disorders, 180, 14-20.

Teferra, S., Hanlon, C., Beyero, T., Jacobsson, L., and Shibre, T. (2013). Perspectives on reasons for non-adherence to medication in persons with schizophrenia in Ethiopia: a qualitative study of patients, caregivers and health workers. BMC Psychiatry, 13, 168.

Thornicroft, G. (2000). National service framework for mental health. The Psychiatrist, 24, 203-206.

Tugwell, P., Bennett, K.J., Sackett, D.L., and Haynes, R.B. (1985). The measurement iterative loop: a framework for the critical appraisal of need, benefits and costs of health interventions. Journal of Chronic Diseases, 38, 339-351.

University of Cambridge (2015). PsyMaptic. http://www.psymaptic.org

Walker, E.R., McGee, R.E., Druss, B.G. (2015). Mortality in mental disorders and global disease burden implications: a systematic review and meta-analysis. JAMA Psychiatry, 72, 334-341.

Wamai, R. (2009). Reviewing Ethiopia’s health system development. Japan Medical Association Journal, 52, 279-286.

While, D., Bickley, H., Roscoe, A., Windfuhr, K., Rahman, S., Shaw, J., et al. (2012). Implementation of mental health service recommendations in England and Wales and suicide rates, 1997-2006: a cross-sectional and before-and-after observational study. Lancet, 379, 1005-1012.

Whiteford, H.A., Degenhardt, L., Rehm, J., Baxter, A.J., Ferrari, A.J., Erskine, H.E., et al. (2013). Global burden of disease attributable to mental and substance use disorders: findings from the Global Burden of Disease Study 2010. Lancet, 382, 1575-1586. World Health Organization (2001a). The world health report 2001: mental health: new understanding, new hope. Geneva: WHO. 
World Health Organization (2001b). Atlas: country profiles on mental health resources 2001. Geneva: WHO.

World Health Organization (2004a). World report on knowledge for better health: strengthening health systems. Geneva: WHO.

World Health Organization (2004b). The Mexico statement on health research. Geneva: WHO.

World Health Organization (2005a). World Health Assembly: resolution on health research. Geneva: WHO.

World Health Organization (2005b). Mental health atlas 2005. Geneva: WHO.

World Health Organization (2008). mhGAP: Mental Health Gap Action Programme: scaling up care for mental, neurological and substance use disorders. Geneva: WHO.

World Health Organization (2009). World Health Organization: the Bamako call to action on research for health. Geneva: WHO.

World Health Organization (2010). mhGAP intervention guide for mental, neurological and substance use disorders in non-specialized health settings: Mental Health Gap Action Programme (mhGAP). Geneva: WHO.

World Health Organization (2011). Mental health atlas 2011. Geneva: WHO.

World Health Organization (2013a). Investing in mental health: evidence for action. Geneva: WHO.

World Health Organization (2013b). Mental health action plan 2013-2020. Geneva: WHO.

World Health Organization (2015a). Evidence-informed policy-making. http://www.who.int/evidence/about/en

World Health Organization (2015b). WHO-AIMS country reports. http://www.who.int/mental_health/who_aims_country_reports/en/ 
World Health Organization Regional Office for Europe (2012). For which strategies of suicide prevention is there evidence of effectiveness? Copenhagen: WHO Regional Office for Europe.

Wimo, A. and Prince, M. (2010). World Alzheimer report 2010. The global economic impact of dementia. London: Alzheimer's Disease International.

World Bank (2015). World development indicators database. http://databank.worldbank.org/data/download/GNIPC.pdf

Young, E. and Quinn, L. (2002). Writing effective public policy papers: a guide to policy advisers in Central and Eastern Europe. Budapest: Open Society Institute. 